\title{
Autophagy and thyroid cancer
}

\author{
Yuji Nagayama \\ Department of Molecular Medicine, Atomic Bomb Disease Institute, Nagasaki University, Nagasaki 852-8523 Japan. \\ Correspondence to: Dr. Yuji Nagayama, Department of Molecular Medicine, Atomic Bomb Disease Institute, Nagasaki University, \\ 1-12-4 Sakamoto, Nagasaki 852-8523 Japan. E-mail: nagayama@nagasaki-u.ac.jp
}

How to cite this article: Nagayama Y. Autophagy and thyroid cancer. J Cancer Metastasis Treat 2021;7:6. http://dx.doi.org/10.20517/2394-4722.2020.114

Received: 16 Oct 2020 First Decision: 24 Dec 2020 Revised: 28 Dec 2020 Accepted: 1 Jan 2021 Published: 15 Jan 2021

Academic Editor: Jerome M. Hershman Copy Editor: Monica Wang Production Editor: Jing Yu

\begin{abstract}
This review provides the up-to-date physiological, pathophysiological, and carcinogenic roles of autophagy in the thyroid. The data on its physiological roles are mainly obtained with genetically engineered mice, demonstrating the importance of autophagy for the maintenance of cell homeostasis and survival as well as provision of building blocks for sufficient synthesis of proteins such as thyroglobulin. Positive and negative controls of autophagic activity by thyrotropin and thyroid hormone, respectively, are now apparent. In thyroid cancer, there is no published study on the role for autophagy in the initiation/development of thyroid cancer, and there exist many inconsistent data regarding its role in established thyroid cancer behavior. For example, definitive conclusions remain to be elucidated regarding the level of autophagic activity in thyroid cancer cells and the effect of autophagy inducers/inhibitors on cancer cell survival/proliferation. Especially, when autophagy is targeted in novel cancer therapeutics, some studies show its pro-survival, but others its anti-survival or context-dependent, effects on thyroid cancer cells. Further studies are in the future necessary to further elucidate the potential of autophagy as a therapeutic target for thyroid cancer.
\end{abstract}

Keywords: Thyroid, cancer, autophagy, pro-survival, anti-survival

\section{INTRODUCTION}

Thyroid cancer is the most common endocrine malignancy with its incidence rate being rapidly increasing during the last several decades ${ }^{[1]}$. The extensive studies on genetic/genomic landscapes of thyroid cancers have identified the aberrant activation of the RAS-RAF-MEK-ERK signaling pathway by the point

\footnotetext{
(c) (1)

(C) The Author(s) 2021. Open Access This article is licensed under a Creative Commons Attribution 4.0 International License (https://creativecommons.org/licenses/by/4.0/), which permits unrestricted use, sharing, adaptation, distribution and reproduction in any medium or format, for any purpose, even commercially, as long as you give appropriate credit to the original author(s) and the source, provide a link to the Creative Commons license, and indicate if changes were made.
}

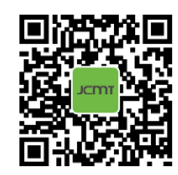


mutations in BRAF or RAS, or chromosomal rearrangements like RET/PTC as the causative role in thyroid carcinogenesis ${ }^{[2]}$. Thyroid cancer can be divided into two subgroups - differentiated [papillary (PTC) and follicular (FTC)] and de-differentiated [poorly differentiated and anaplastic (ATC)] types. PTC is the most common type, in which the mutant BRAF $\left(\mathrm{BRAF}^{\mathrm{V} 600 \mathrm{E}}\right.$ ) has been shown to be the most frequent driver mutation, followed by RET/PTC and the mutant RAS ${ }^{[2]}$. Surgery, radioactive iodine (RAI) treatment with ${ }^{131} \mathrm{I}$ and thyrotropin (TSH) suppression therapy have long been choices of treatment modalities for thyroid cancer. In most patients with thyroid cancers, disease remission is achieved by these modalities, but recurrence does occur in a subgroup of patients who acquired RAI resistance as a result of dedifferentiation. Tyrosine kinase inhibitors have recently been approved as an additional therapeutic choice for thyroid cancer treatment, especially for RAI refractory thyroid cancer, which clearly exhibit its therapeutic benefits, but at the same time show some problems such as severe adverse effects and/or intrinsic/acquired resistance. Thus, more novel therapeutic approach is urgently needed to be introduced. Targeting autophagy may have a potential for this purpose.

Autophagy is an essential pathway mediating the degradation of cellular components such as proteins and organelles in the lysosomes. It not only occurs constitutively at basal rate under physiological conditions to maintain homeostasis for intracellular recycling of the metabolites and metabolic regulation, but it is also induced during various physiological and pathological conditions such as nutritional starvation ${ }^{[3,4]}$. Alterations in autophagic activity have been widely considered to play crucial roles in numerous diseases such as degenerative disorders, metabolic diseases, aging, and cancer, among others. There are three types of autophagy so far identified in mammalian cells: macroautophagy (hereafter referred to as "autophagy"), microautophagy, and chaperone-mediated autophagy (CMA). This review mainly focuses on macroautophagy.

\section{AUTOPHAGY IN PHYSIOLOGY}

\section{Autophagic flux}

In the autophagy process, a special structure called the "phagophore" is first formed from the endoplasmic reticulum or other intracellular membranes in a cell, which engulf the cellular contents and targeted proteins/organelles. Upon the complete engulfment by its enclosure, it becomes the "autophagosome" and fuses with the lysosome forming the "autolysosome" and then delivers its contents into the lumen of the lysosome for degradation. There are two kinds of autophagy, non-selective, and selective. Nonselective autophagy engulfs a part of the cytoplasm as cargo, while selective autophagy recognizes a specific cargo such as damaged organelles/protein aggregates; an example is mitophagy - selective autophagy for mitochondria. The highly simplified schema depicting the autophagic flow and a representative autophagy inducer [rapamycin, an inhibitor for mechanistic target of rapamycin (mTOR)] and inhibitors [3-methyladenine (3-MA) and chloroquine (CQ)] is shown in Figure 1. Although more than 30 proteins are involved in autophagy, most are omitted and only those appear in this review are shown in Figure 1. For more details, refer to the following references ${ }^{[3,4]}$.

\section{Monitoring of autophagic flux}

It is important to precisely measure autophagic activity to correctly understand the role for autophagy in pathophysiology. This is very critical because the appropriate analyses have not always been done in many previous studies on the role for autophagy in thyroid cancer (see "NOTES" below).

To correctly evaluate autophagic activity, flux through autophagy pathway should be measured. Mere determination of the amounts of autophagy-related proteins does not necessarily suffice this purpose. Microtubule-associated protein 1 light chain 3 (LC3) and p62/sequestosome 1 (SQSTM1, an adaptor molecule for selective autophagy) are two representative molecules among those used as biomarkers for monitoring autophagic flux ${ }^{[5]}$. As autophagy proceeds, LC3-I, ubiquitously expressed in the cytoplasm, 


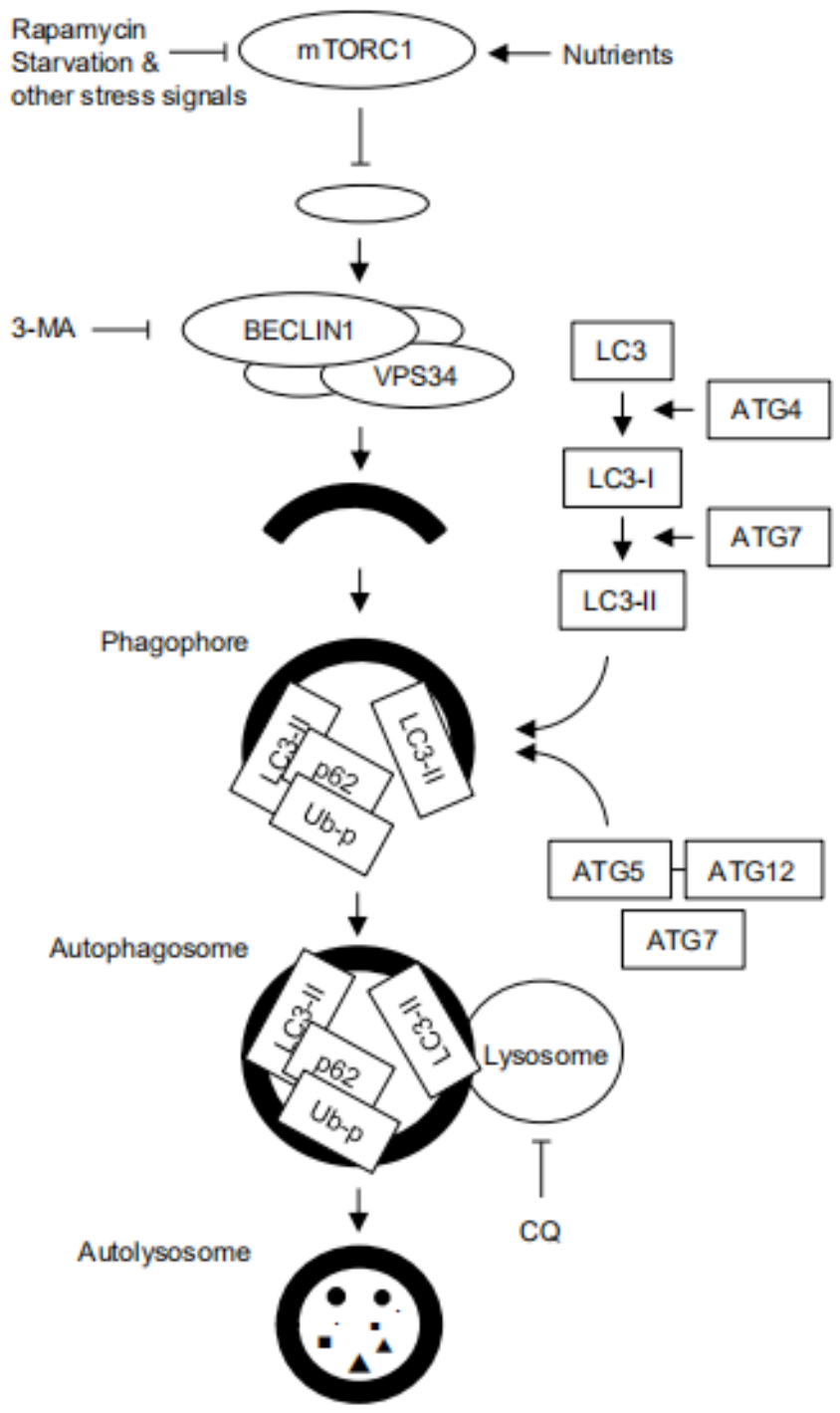

Figure 1. Schematic representation of autophagic flux. Autophagy starts with formation of phagophore (the initiation step), followed by the nucleation step where class III phosphatidylinositol 3-kinase (PI3K) complex, containing BECLIN-1, VPS34, and other molecules, elongates phagophore and encapsulates the cargo that should be degraded, result in formation of autophagosome. The next elongation step involves two ubiquitin like conjugation systems - the LC3-PE and ATG5-ATG12 systems. In the former, processed and lipidated LC3 (LC3-II) is recruited to the phagophore/autophagosome, as is p62, an adaptor molecule for selective autophagy of ubiquitinated proteins (Ub-p). The latter is essential for proper curvature of the phagosome. ATG7 is involved in both systems. The autophagosome then fuses with the lysosome to form autolysosome, in which the cargo is degraded by the lysosomal enzymes. mTOR negatively controls autophagic activity, whose activity is controlled positively by nutrients and negatively by rapamycin and other stress signals such as starvation. 3-MA inhibits autophagy at the early step of autophagic flux by inhibiting class III PI3K, and chloroquine at its late step by raising the lysosomal $\mathrm{pH}$ and then inhibiting the fusion between the autophagosome and the lysosome. LC3: light chain 3; CQ: chloroquine; 3-MA: 3-methyladenine

is converted to LC3-II by lipidation, conjugated with phosphatidylethanolamine (PE) and possibly phosphatidylserine, and is recruited to the autophagosome. The amount of LC3-II can be monitored by Western blotting (WB) showing the presence of a LC3-II band in addition to a LC3-I band, and by immunohistochemistry or immunofluorescence showing alteration of LC3 staining pattern from diffuse to punctate appearance. Although the molecular weight of LC3-II is higher than that of LC3-I (16 to $18 \mathrm{kDa}$ ) because of addition of lipid, LC3-II migrates faster in gel due to its high hydrophobicity and can be detected as a 14 to $16 \mathrm{kDa}$ band in WB. However, at the same time, LC3-II is degraded by the lysosomal digestion in autophagic flux, so that the amount of LC3-II is determined by balance between the rate of conversion from LC3-I to LC3-II and degradation in the lysosome. p62 is a typical substrate of autophagy and is degraded 


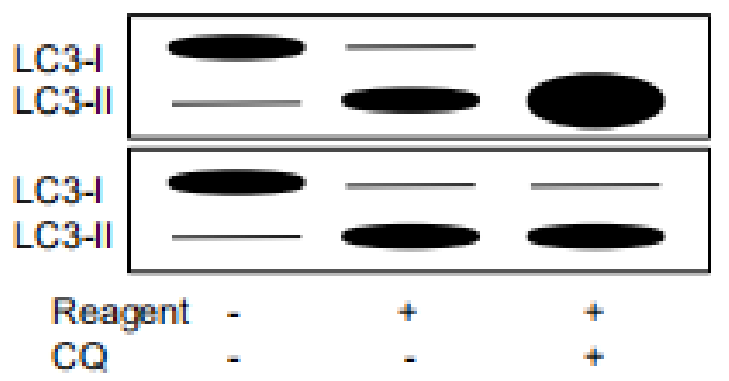

Figure 2. Alterations in relative amounts of LC3-I and II by autophagy inducer and inhibitor in Western blotting. A reagent increases amounts of LC3-II in both upper and lower panels. However, a further increase in LC3-II by combination of the reagent and chloroquine indicate that the reagent is an autophagy inducer, but when the reagent is an inhibitor, amounts of LC3-II remains unchanged in combination of the reagent and chloroquine. LC3: light chain 3; CQ: chloroquine

in the autolysosome. The amounts of $\mathrm{p} 62$ can also be determined by WB and immunohistochemistry or immunofluorescence.

Thus, in a typical case, increased amount of LC3-II and decreased amount of p62 indicate elevated autophagic flux. In the case of autophagy inhibition, the alterations in the amounts of LC3-II and p62 depend on which step is inhibited. For example, 3-MA, which blocks autophagy at its initial step ${ }^{[6]}$, decreases LC3-II and increases p62, but CQ, which blocks autophagy at its late step ${ }^{[7]}$, increases both LC3-II and p62. However, what is complicated is that the reverse of the latter is not always true, that is, increased LC3-II and p62 does not necessarily mean autophagy inhibition. This is because the p62 level is controlled not only by its degradation by autophagy but also by its synthesis rate; when synthesis rate exceeds degradation rate, p62 levels may increase even if autophagy is active. Indeed, transcriptional/ posttranscriptional increases in p62 levels are reported in certain conditions ${ }^{[8-11]}$. Therefore, an additional experiment in which the cells are treated with a reagent of your interest, an autophagic inhibitor (which inhibits autophagy at the late step like CQ) and their combination for comparison of LC3-II levels should be performed to confirm its effect on autophagic flux (see references ${ }^{[5,12]}$ for more details). Briefly, an additive or supra-additive effect of the combination on LC3-II levels likely indicate enhanced effect of autophagic flux by the reagent, while no additive effect suggests a blockade of autophagy [Figure 2].

The plasmids expressing green fluorescence protein (GFP)-LC3 or red fluorescence protein (RFP)-GFPLC3 are also frequently used for autophagy flux monitoring ${ }^{[5]}$. GFP puncta in immunofluorescence represent autophagosome, not autolysosome, formation with the GFP-LC3 vector because GFP fluorescence is quenched in low $\mathrm{pH}$ of the lysosome, which therefore indicate formation of autophagosome and does not indicate completion of autophagy flux. In contrast, in the RFP-GFP-LC3 vector, yellow color, signifying co-localization of red and green fluorescence, indicates formation of autophagosome while red indicates formation of autolysosome where red is preserved but green is quenched in the lysosome; the latter indicates completion of autophagic flux.

\section{Physiological roles for autophagy}

In general

Indispensable role for basal level of autophagy for maintaining homeostasis was clearly shown systematically by genetically engineered mice. Thus, systemic disruption of Atg5 or Atg7 genes caused neonatal death, that is, the knockout $(\mathrm{KO})$ mice died within a day after birth ${ }^{[13,14]}$. Organ-specific KO induced tissue degeneration in neuron, liver, heart and pancreatic $\beta$-cells ${ }^{[15-18]}$. The crucial role for autophagy in development and differentiation of numerous other tissues have also been reported ${ }^{[3]}$. These data clearly indicate the principal role for autophagy in development and differentiation of many different types of cells. However, even in the physiological condition, it is also true that excessive or prolonged autophagy leads to cell death called "autophagy-regulated cell death" ${ }^{\text {"19,20] }}$. 


\section{In thyroid}

The physiological role for autophagy in thyroid was studied using genetically engineered mice. We generated the thyroid specific Atg5, a component of the autophagy machinery [Figure 1], KO mice Atg $5^{f l o x / f o x}$; TPO-Cre $\left(\operatorname{Atg}^{\text {thyr-KO}}\right)^{[21]}$. These KO mice were born with an expected Mendelian trait and in euthyroid state during the 1-year-observational period. However, accumulation of ubiquitinated proteins was detected at 4 months, and apoptotic cell death, decreased number of thyroid follicular epithelial cells (thyrocytes), and increased DNA damages detected by 8 -hydroxy-2'-deoxyguanosine (8-OHdG) and p53-binding protein $1(53 \mathrm{BP} 1)$ foci were observed at 8 and 12 months, indicating the critical role of basal level of autophagic activity in thyrocyte survival and homeostasis.

To study the significance of induced autophagy in a stressed condition, we first clarified regulation of autophagic activity by hormones, finding the positive control by TSH and the negative control by thyroid hormone $\mathrm{T}_{4}^{[1]}$. When $\mathrm{KO}$ mice were treated with methimazole and perchlorate, which induce increased TSH and decreased $\mathrm{T}_{4}$ levels (as a net effect, induce autophagy), smaller follicle sizes and lower thyroglobulin (TG) contents in thyrocytes were observed as compared to control mice, implying impaired TG production presumably by diminished nutrient supply due to a lack of autophagy. Altogether, basal level of autophagy is required for maintenance of cell homeostasis and survival, and induced autophagy, elicited by elevated TSH and decreased thyroid hormone, supports the provision of building blocks for sufficient synthesis of proteins including TG.

KO mice with disrupted Vps34 gene, a component of class III PI3K (a more upstream molecule than ATG5 in autophagic flow; see Figure 1) were also generated ${ }^{[22]}$. Vps $34^{f l o x / f o x[11]}$; Paxs-Cre $\left(\operatorname{Vps} 34^{c K O}\right)$ mice were also born normally but died at approximately 1 month of age; they had severe hypothyroidism, impaired TG iodination, abnormal TG trafficking, defective lysosomal proteolysis, and the presence of macrophages eating iodinated TG in the lumen were observed. More pronounced phenotype alterations in Vps $34^{c K O}$ mice are evident when comparing to $A \operatorname{tg} 5^{\text {thyr-KO}}$ mice, which may be explained by autophagy-independent functions of autophagy-related proteins ${ }^{[23]}$. Indeed, the findings in the latter seem to be at least in part attributed to the role for VPS34 in vesicular trafficking rather than autophagic activity.

\section{AUTOPHAGY IN CANCER}

\section{Cancer initiation}

In general

It is well accepted that autophagy has the dual effects on cell survival and death, that is, it on one hand supports cell survival by providing nutrients required for maintaining cellular homeostasis, but on the other hand promotes cell death, i.e., autophagy-regulated cell death ${ }^{[19,20]}$. Particularly in cancer, it is proposed that autophagy suppresses tumor development in the early stage of tumorigenesis, while autophagy promotes tumor survival and proliferation once a tumor develops ${ }^{[24]}$. Therefore, numerous preclinical and clinical studies on autophagy-targeted treatment mainly focused on autophagy inhibitors ${ }^{[24,25]}$. However, the data so far accumulated are not so simple, and even in established cancers, studies show therapeutic effect of not only autophagy inhibitors but also autophagy inducers on tumor growth ${ }^{[24,26]}$.

Much evidence indicating the role for autophagic activity in the initial step of cancer development comes from the studies with genetically engineered mice. Beclin-1 heterozygous KO mice developed spontaneous lung cancers, liver cancers, and lymphomas, and accelerated the development of HBV-induced liver premalignant lesions ${ }^{[27,28}$. Systemic mosaic Atg5 $\mathrm{KO}$ and liver-specific Atg7 $\mathrm{KO}$ mice developed benign liver adenomas ${ }^{[29,30]}$. Although accumulated p62, commonly observed in all $\mathrm{KO}$ mice, is thought to play a role for tumorigenesis ${ }^{[30,31]}$, development of cancers in multiple organs in Beclin-1 heterozygous $\mathrm{KO}$ mice as compared to that of benign tumors only in liver in systemic mosaic Atg5 $\mathrm{KO}$ and liver-specific Atg7 KO mice may indicate autophagy-independent anti-tumorigenic function of BECLIN-1; for example, BECLIN- 
1-controls of apoptosis ${ }^{[32]}$ and of $\mathrm{p}^{\left[3^{[33]}\right.}$. It is also reported that Atg4 $\mathrm{KO}$ itself did not induce any tumor development, but increased incidence of chemically induced fibrosarcoma ${ }^{[34]}$.

Of interest, Atg5 or Atg7 KO mice were crossed with other genetically engineered mice having various oncogenes or a loss-of-function mutation of tumor suppressor gene such as the mutant RAS, BRAF or p5 $3^{[35]}$. In most of these double mutant mice, tumor development was accelerated but tumors did not progress to malignancy and, instead, turned to be benign oncocytic tumors ${ }^{[36-40]}$. Oncocytic tumor has abundant mitochondria, which is thus likely attributed to defective mitophagy, a selective autophagy. Therefore, impaired mitophagy and/or accumulated mitochondria appear to block progression from benign to malignancy. Accumulation of deformed and dysfunctional mitochondria was also observed in liver adenomas in liver-specific Atg7 KO mice mentioned above ${ }^{[29,30]}$.

Altogether, it is clear that autophagy works as a tumor suppressor in the early step of tumorigenesis. However, there is always an exception; development of some tumors such as RAS-driven cancers are reported to be dependent on autophagy activation ${ }^{[41]}$.

Impaired autophagy is also strongly associated with abnormal DNA damage repair ${ }^{[42]}$, especially abnormal homologous recombination ${ }^{[43]}$, which may also explain the propensity of autophagy-defective mice to tumor development. Indeed, genomic instability was suggested by the presence of $\gamma \mathrm{H} 2 \mathrm{AX}$ foci (indicating DNA double strand breaks) in liver adenomas in Atg7 $\mathrm{KO}$ mice ${ }^{[29,30]}$.

\section{In thyroid}

In thyroid cancer, there is no published study on cancer development using autophagy KO mice. In our preliminary study, no thyroid tumor development was observed in thyroid-specific autophagy KO

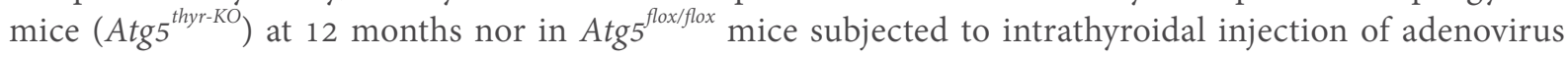
expressing Cre recombinase under TG promoter in the 18-month-experimental period (unpublished data). Instead, a study on a human genetic disease provides a clue as to the relationship between autophagy and thyroid carcinogenesis. Thus, a previous study has shown that, in human Cowden syndrome with the mutant succinate dehydrogenase D-G12S or D-H50R, suppression of autophagy by these mutations and subsequent ROS elevation and phosphatase and tensin homolog (PTEN) inactivation may be involved in thyroid tumorigenesis ${ }^{[44]}$. Furthermore, SNPs in autophagy-related genes such as Atg5 and Atg16L are reported to be associated with development of thyroid cancer and RAI resistance ${ }^{[45,46]}$.

As mentioned above, oncocytoma is usually a benign tumor. However, the thyroid is an exception, where it is sometimes malignant (called Hürthle cell carcinoma). In this regard, we have recently found that accumulation of mitochondria in thyroid oncocytic tumor is caused (1) by defective expression of mitochondria-eating protein $(\mathrm{MIEAP})^{[47]}$, which play a central role in a non-canonical mitophagy ${ }^{[48]}$; and (2) by enhanced biogenesis of mitochondria which compensates defective function of mitochondria complex I ${ }^{[49]}$. It is reported that the defective PARK2-mediated canonical mitophagy by a loss-of-function mutation in PARK2 gene also causes mitochondrial accumulation in a thyroid malignant oncocytoma cell line XTC. UC1, but loss of function mutation in autophagy-related genes including PARK2 is rare in thyroid oncocytoma in humans ${ }^{[50,51]}$. Therefore, in experimental mouse models of cancer in nonthyroid tissues (see above), a defect in canonical mitophagy may be sufficient, but in human thyroid, both defective mitophagy (i.e., a defect in either MIEAP-mediated non-canonical or PARK2-mediated canonical mitophagy) and increased compensated mitochondrial biogenesis may be required for oncocytic phenotype. 


\section{Established cancer}

Autophagic activity in thyroid cancer

In established cancers, irrespective of those derived from the thyroid or other organs, it is controversial whether autophagic activity is elevated or not. In thyroid cancers, autophagic activity is reported lower in PTCs, especially those with lymph node metastasis, by demonstrating lower LC3-II expression levels in WB (NOTE - p62 levels were not studied.) ${ }^{[52]}$ and by lower expression levels of LC-3 protein in immunofluorescence (NOTE - LC3 puncta, not LC3 expression levels, should be quantified in immunofluorescence $)^{[53]}$, while no difference was found in number of LC3 puncta in immunofluorescence between benign (including normal, Graves', goiter, and follicular adenoma tissues) and malignant (including FTC, PTC, follicular variant PTC, and ATC) lesions ${ }^{[54]}$. Lower autophagic activity in thyroid cancer can be explained by the fact that the oncogene-stimulated RAS-RAF-MEK-ERK and mTOR signaling pathways inhibit autophagy ${ }^{[55,56]}$. In general, oncogenic proteins inhibit, but oncosuppressor proteins induce autophagy ${ }^{[57]}$. On the other hand, BRAF-activated long non-coding RNA (BANCR), which is overexpressed in PTCs, contributes to cell proliferation and activates autophagy as demonstrated by increased and decreased LC3-II levels by overexpression and knockdown (KD), respectively, of BANCR in WB (NOTE - p62 levels were not studied) ${ }^{[58]}$. $\mathrm{BRAF}^{\mathrm{V} 600 \mathrm{E}}$-induced chronic endoplasmic reticulum stress ${ }^{[59]}$ and NOXA upregulation are also thought to be reasons for $\mathrm{BRAF}^{\mathrm{V} 600 \mathrm{E}}$-mediated autophagy activation in melanoma ${ }^{[60]}$. The associations of $\mathrm{BRAF}^{\mathrm{V} 600 \mathrm{E}}$ and higher expression levels of autophagy-related proteins (LC3 and p62) ${ }^{[61]}$ and higher expression of BECLIN-1 ${ }^{[62]}$ are noted in PTCs. Up-regulation of LC3-II expression is also reported to be associated with hypoxia-inducible factor-1 $\alpha$ (HIF-1 $\alpha$ ) and telomerase reverse transcriptase (TERT) in PTCs ${ }^{[63]}$. Of note, higher expression levels of autophagy-related proteins do not necessarily mean higher autophagic activity.

Finally, CMA is shown increased in PTCs as demonstrated by overexpression of lysosome-associated membrane protein type $2 \mathrm{~A}$ (LAMP2A) (NOTE - the flux of this type of autophagy cannot be examined ${ }^{[64]}$.

\section{Autophagy as biological markers for thyroid cancer}

Different groups report the distinct autophagy-related gene sets as biological markers for thyroid cancer. Zhu et al. ${ }^{[65]}$ reported three genes related to prognosis: inositol 1,4,5-triphosphate receptor type 1 (ITPR1), chemokine C-C motif ligand 2 (CCL2) and cyclin-dependent kinase inhibitor $2 A$ (CDKN2A). Zhang et al. ${ }^{[66]}$ reported two genes related to aggressiveness and prognosis: BECLIN-1 and aplasia Ras homolog member I $(A R H 1)$. A positive correlation between LC3-II levels and urinary iodine concentrations is also reported in thyroid cancer patients ${ }^{[67]}$.

\section{Autophagy-targeted therapy}

Regarding the results of autophagy-targeted therapy, reports can be divided into three categories; the first supporting pro-survival/proliferative effect of autophagy on thyroid cancer cells [Table 1], second supporting anti-survival/proliferative effects [Table 2], and the third suggesting cell-context-dependent effects [Table 3].

(1) Studies reporting pro-survival/proliferative effect of autophagy on thyroid cancer

In the first group demonstrating the pro-survival effect of autophagy on thyroid cancer cells [Table 1], anti-tumor effects of autophagy inhibitors - CQ, 3-MA, and genetic KD of autophagy related proteins - are inconsistent; CQ is effective in $8505 \mathrm{C}$, FTC133, and TPC1 cells ${ }^{[63,68]}$ as well as BCPAP cells ${ }^{[69]}$ (concentration used: $10 \mu \mathrm{M})$, but not in BCPAP and FRO cells ${ }^{[70]}, \mathrm{KHM}^{-5 M}$ and C643 cells ${ }^{[71]}$, and K-1 cells ${ }^{[72]}(10-20 \mu \mathrm{M})$. Another autophagy inhibitor 3-MA is reported to suppress cell growth in BCPAP cells ${ }^{[67]}(5 \mathrm{mM})$, but not in KHM-5M and C643 cells ${ }^{[71]}$, TPC1 cells ${ }^{[73]}$, SW579 cells ${ }^{[74]}$, and BCPAP ${ }^{[75,76]}$ (1-3 mM). Genetic ablation of autophagy by ATG5 KD was also shown to kill $8505 \mathrm{C}$ and FTC-133 cells ${ }^{[68]}$, and by ATG7 KD in BCPAP and TPC1 cells ${ }^{[63,69]}$. It should be noted here that CQ has also been reported to have an autophagyindependent anti-cancer effect ${ }^{[77-79]}$. 
Table 1. Summary of the articles reporting pro-proliferative/tumorigenic action of autophagy

\begin{tabular}{|c|c|c|c|c|}
\hline & TC cell lines used ${ }^{*}$ & $\begin{array}{c}\text { The effects on cell growth/ } \\
\text { survival }\end{array}$ & $\begin{array}{c}\text { The effects of autophagy } \\
\text { inhibition }\end{array}$ & Ref. \\
\hline \multicolumn{5}{|c|}{ Autophagy inhibitors } \\
\hline $\mathrm{CQ}$ & 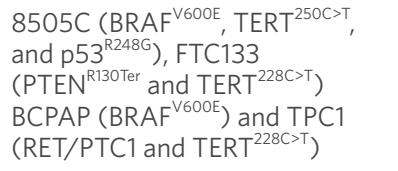 & $\begin{array}{l}\text { Inhibition of cell growth, colony } \\
\text { formation and Induction of } \\
\text { apoptosis }\end{array}$ & & {$[63,68,69]$} \\
\hline 3-MA & BCPAP & Inhibition of cell growth & & {$[67]$} \\
\hline ATG5 KD & $8505 \mathrm{C}$ and FTC133 & Induction of apoptosis & & {$[68]$} \\
\hline ATG7 KD & BCPAP and TPC1 & Induction of apoptosis & & {$[63,69]$} \\
\hline \multicolumn{5}{|c|}{ Autophagy stimulators } \\
\hline BANCR & $\begin{array}{l}\mathrm{IHH}-4\left(\mathrm{BRAF}^{\mathrm{V} 600 \mathrm{E}} \text { and }\right. \\
\left.\mathrm{TERT}^{228 C \mathrm{~T}}\right)\end{array}$ & $\begin{array}{l}\text { Stimulation of cell survival and } \\
\text { proliferation }\end{array}$ & $\begin{array}{l}\text { Inhibition of cell growth and } \\
\text { induction of apoptosis by 3-MA }\end{array}$ & {$[58]$} \\
\hline LAMP2A & $\begin{array}{l}\mathrm{K} 1\left(\mathrm{BRAF}^{\mathrm{V} 600 \mathrm{E}} \text { and } \mathrm{TERT}^{228 \mathrm{C}>\mathrm{T}}\right) \\
\mathrm{W}^{\#} \text { and } \mathrm{TPC1}\end{array}$ & $\begin{array}{l}\text { Induction of chaperon-mediated } \\
\text { autophagy and promotion of } \\
\text { tumor cell proliferation and } \\
\text { migration }\end{array}$ & $\begin{array}{l}\text { Suppression of tumor cell } \\
\text { proliferation and migration by } \\
\text { LAMP2A shRNA }\end{array}$ & {$[64]$} \\
\hline Sorafenib & $8505 \mathrm{C}$ and $\mathrm{FTC133}$ & $\begin{array}{l}\text { Inhibition of cell growth and } \\
\text { Induction of apoptosis }\end{array}$ & $\begin{array}{l}\text { Augmentation of sorafenib- } \\
\text { induced cell growth inhibition } \\
\text { and apoptosis by ATG5 siRNA } \\
\text { and CQ }\end{array}$ & {$[68]$} \\
\hline Vemurafenib & BCPAP, FRO and $8505 C$ & $\begin{array}{l}\text { Induction of cell death (relatively } \\
\text { resistant) }\end{array}$ & $\begin{array}{l}\text { Sensitization to vemurafenib- } \\
\text { induction of cell death by HCQ } \\
\text { and ATG5 siRNA }\end{array}$ & {$[70,76]$} \\
\hline Apatinib & 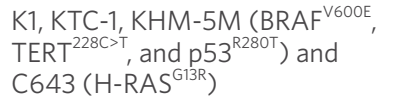 & $\begin{array}{l}\text { Induction of cell growth arrest } \\
\text { and apoptosis }\end{array}$ & $\begin{array}{l}\text { Enhancement of apatinib- } \\
\text { induced apoptosis by HCQ, } \\
\text { 3-MA and ATG5 siRNA }\end{array}$ & {$[71,72]$} \\
\hline CZ415 & TPC1 & $\begin{array}{l}\text { Induction of cell death and } \\
\text { inhibition of colony formation }\end{array}$ & $\begin{array}{l}\text { Sensitization to CZ415-induced } \\
\text { cytotoxicity by 3-MA and } \\
\text { BECLIN-1 shRNA }\end{array}$ & [73] \\
\hline Radiation & SW-579 (HTB-107) & Induction of apoptosis & $\begin{array}{l}\text { Enhancement of radiation- } \\
\text { induced apoptosis by 3-MA and } \\
\text { BECLIN-1 siRNA }\end{array}$ & {$[74]$} \\
\hline Cisplatin & 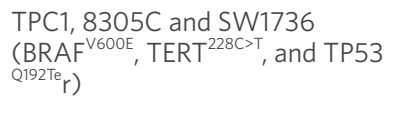 & Induction of cell death & $\begin{array}{l}\text { Sensitization to cisplatin-induced } \\
\text { cell death by } 3-M A, C Q \text {, miR- } \\
144 \text { and miR30d (a BECLIN-1 } \\
\text { expression suppressor) }\end{array}$ & {$[80,81]$} \\
\hline Flavokawain B & WRO (BRAF $\left.{ }^{\mathrm{V} 000 \mathrm{E}}\right)$ and TPC1 & $\begin{array}{l}\text { Induction of apoptosis and } \\
\text { mitochondrial dysfunction }\end{array}$ & $\begin{array}{l}\text { Sensitization to flavokawain } \\
\text { B-induced apoptosis by 3-MA, } \\
\text { CQ and BECLIN-1 siRNA }\end{array}$ & {$[82]$} \\
\hline $\begin{array}{l}\text { EBSS-induced } \\
\text { starvation }\end{array}$ & $\begin{array}{l}\mathrm{FRO}^{\#}, \mathrm{KTC}^{-1}\left(\mathrm{BRAF}^{\mathrm{V} 600 \mathrm{E}} \text { and }\right. \\
\left.\mathrm{TERT}^{250 \mathrm{C}>\mathrm{T}}\right) \text { and } \mathrm{KTC}^{-3} 3^{\#}\end{array}$ & A slight cell death & $\begin{array}{l}\text { An increase in apoptotic cell } \\
\text { death by autophagy inhibitors } \\
\text { (BAG3 and 3-MA) }\end{array}$ & {$[83]$} \\
\hline TERT & BCPAP and TPC1 & $\begin{array}{l}\text { Increases in cell proliferation, } \\
\text { migration and invasion, and a } \\
\text { decrease in apoptosis }\end{array}$ & $\begin{array}{l}\text { An increase in apoptosis and } \\
\text { decreases in cell proliferation, } \\
\text { migration and invasion by TERT } \\
\text { shRNA }\end{array}$ & [63] \\
\hline
\end{tabular}

CQ: chloroquine; 3-MA: 3-methyladenine; EBSS: Earle's Balanced Salt Solution; BANCR: BRAF-activated IncRNA; LAMP2A: Iysosomeassociated membrane protein type 2A; BAG3: Bcl-2-associated athanogene 3; TERT: telomerase reverse transcriptase. *genotypes are from https://web.expasy.org/cellosaurus/ and ${ }^{[112]}$; ${ }^{\#}$ genotypes not reported

Autophagy inducers so far reported to show the pro-survival/proliferative effect of autophagy include $\mathrm{BANCR}^{[58]}, \mathrm{LAMP}_{2} \mathrm{~A}^{[64]}$, tyrosine kinase inhibitors [sorafenib (a pan-tyrosine kinase inhibitor) and vemurafenib (a BRAF inhibitor)] $)^{[68,70,76]}$, apatinib (a VEGF2 inhibitor) ${ }^{[11,72]}$, CZ415 (an mTOR inhibitor) ${ }^{[73]}$, radiation $^{[74]}$, $\operatorname{cisplatin}^{[80,81]}$, flavokawain $\mathrm{B}^{[82]}$ Earle's Balanced Salt Solution-induced starvation ${ }^{[83]}$, and TERT $^{[63]}$ [Table 1]. NOTE - among them, some data are not convincing. For example: (1) although the authors interpret their data showing augmentation of sorafenib-induced apoptosis by ATG5 KD in thyroid cancer cell lines $8505 \mathrm{C}$ and FTC133 as indicating the pro-survival effect of autophagy, sorafenib and ATG5 KD individually induced apoptosis and the effect of their combination look merely additive (or less than additive $)^{[68]}$; (2) autophagic activity was not evaluated in the CZ415 study ${ }^{[73]}$; and (3) only LC3-II 
Table 2. Summary of the articles reporting anti-tumorigenic action of autophagy

\begin{tabular}{|c|c|c|c|c|c|}
\hline & TC cell lines used & $\begin{array}{l}\text { The effect on cell } \\
\text { growth/survival }\end{array}$ & The effect of KD & $\begin{array}{c}\text { The effects of autophagy } \\
\text { inhibition }\end{array}$ & Ref. \\
\hline \multicolumn{6}{|c|}{ Autophagy inhibitors } \\
\hline $\mathrm{BIRC7}$ & $\begin{array}{l}\text { BCPAP, TPC1, } \mathrm{K} 1 \text { and } \\
\mathrm{IHH}-4\end{array}$ & $\begin{array}{l}\text { Promotion of tumor growth } \\
\text { and migration/invasion }\end{array}$ & $\begin{array}{l}\text { Inhibition of BIRC7- } \\
\text { induced tumor growth } \\
\text { and migration/invasion by } \\
\text { BIRC7 KD }\end{array}$ & & {$[85]$} \\
\hline miRNA-221/222 & $\mathrm{K} 1$ & $\begin{array}{l}\text { Inhibition of apoptosis } \\
\text { Promotion of migration and } \\
\text { invasion } \\
\text { Suppression of ATG10 } \\
\text { expression }\end{array}$ & $\begin{array}{l}\text { Suppression of } \\
\text { miRNA-221/222 inhibitor- } \\
\text { induction of apoptosis by } \\
\text { ATG10 siRNA }\end{array}$ & & {$[86]$} \\
\hline \multicolumn{6}{|c|}{ Autophagy stimulators } \\
\hline Apigenin & BCPAP & $\begin{array}{l}\text { Induction of autophagic cell } \\
\text { death and } \mathrm{G} 2 / \mathrm{M} \text { arrest }\end{array}$ & & $\begin{array}{l}\text { Blockade of apigenin- } \\
\text { induction of cell death by } \\
\text { 3-MA }\end{array}$ & {$[75]$} \\
\hline Sanguinarine & BCPAP and TPC1 & $\begin{array}{l}\text { Inhibition of cell } \\
\text { proliferation, and induction } \\
\text { of ROS and apoptosis }\end{array}$ & & $\begin{array}{l}\text { Abolishment of } \\
\text { sanguinarine's anti-cancer } \\
\text { effect by NAC-mediated } \\
\text { ROS inhibition }\end{array}$ & [87] \\
\hline Aloperine & $\begin{array}{l}\mathrm{KMH}-2\left(\mathrm{~N}-\mathrm{RAS}^{\mathrm{Q} 61 \mathrm{R}}\right. \\
\text { and TERT } \\
\mathrm{IHH}-4\end{array}$ & Induction of cell death & & $\begin{array}{l}\text { Impairment of aloperine- } \\
\text { induced cell death effect by } \\
\text { 3-MA }\end{array}$ & {$[88]$} \\
\hline $\begin{array}{l}\text { IncRNA GAS8- } \\
\text { AS1 }\end{array}$ & TPC1 and BCPAP & $\begin{array}{l}\text { Inhibition of cell } \\
\text { proliferation }\end{array}$ & & $\begin{array}{l}\text { Impairment of anti- } \\
\text { proliferative effect of } \\
\text { IncRNA GAS8-AS1 by ATG5 } \\
\text { siRNA }\end{array}$ & {$[91]$} \\
\hline Allicin & SW1736 and Hth-7 & Inhibition of cell survival & & $\begin{array}{l}\text { Abolishment of anti- } \\
\text { survival effect of allicine by } \\
\text { 3-MA and CQ }\end{array}$ & {$[89,90]$} \\
\hline $\begin{array}{l}\text { Mulberry } \\
\text { anthocyanin }\end{array}$ & $\begin{array}{l}\text { SW1736 and Hth- } \\
7\left(\mathrm{~N}-\mathrm{RAS}^{\mathrm{Q61R}} \text { and }\right. \\
\left.\text { TERT }^{250 C>T}\right)\end{array}$ & Induction of apoptosis & & $\begin{array}{l}\text { Abolishment of mulberry- } \\
\text { induced apoptosis by 3-MA } \\
\text { and CQ }\end{array}$ & {$[90]$} \\
\hline Doxorubicin & TPC1 and $8505 \mathrm{C}$ & Induction of cell death & & $\begin{array}{l}\text { Impairment of doxorubicin/ } \\
\text { radiation-induced cell } \\
\text { death by 3-MA }\end{array}$ & {$[92]$} \\
\hline \multicolumn{6}{|l|}{ Radiation } \\
\hline RAD001 & TPC1 and $8505 \mathrm{C}$ & $\begin{array}{l}\text { Sensitization to doxorubicin } \\
\text { and radiation }\end{array}$ & & $\begin{array}{l}\text { Abolishment of sensitizing } \\
\text { effect of RAD001 by ATG5 } \\
\text { siRNA }\end{array}$ & {$[93]$} \\
\hline Sirtuin 6 & TPC1 and K1 & $\begin{array}{l}\text { Inhibition of in vivo tumor } \\
\text { growth }\end{array}$ & & $\begin{array}{l}\text { Cancellation of Sirtuin } \\
6 \text {-mediated tumor growth } \\
\text { inhibition by CQ }\end{array}$ & {$[97]$} \\
\hline
\end{tabular}

IncRNA GAS8-AS1: long non-coding RNA GAS8 antisense RNA 1; BIRC7: baculoviral IAP repeat containing 7; KD: knockdown; CQ: chloroquine; 3-MA: 3-methyladenine

Table 3. Summary of the articles reporting context-dependent effect of autophagy modulators on cancer behavior

\begin{tabular}{|c|c|c|c|c|}
\hline $\begin{array}{l}\text { Autophagy } \\
\text { modulators }\end{array}$ & TC cell lines used & $\begin{array}{l}\text { The effects on autophagy and } \\
\text { cell growth/survival }\end{array}$ & The effects of autophagy inhibition & Ref. \\
\hline \multirow[t]{2}{*}{ TRAIL } & TPC1 & $\begin{array}{l}\text { Induction of autophagy and cell } \\
\text { death }\end{array}$ & $\begin{array}{l}\text { Impairment of TRAIL-induced cell death } \\
\text { by ATG7 siRNA (indicating anti-survival } \\
\text { effect of TRAIL-induced autophagy) }\end{array}$ & [98] \\
\hline & FRO & $\begin{array}{l}\text { Induction of cell death but not } \\
\text { autophagy }\end{array}$ & $\begin{array}{l}\text { Impairment of TRAIL-induced cell death } \\
\text { by ATG7 siRNA (indicating anti-survival } \\
\text { effect of basal level of autophagy) }\end{array}$ & \\
\hline \multirow[t]{2}{*}{ FAM129A } & $\begin{array}{l}\text { PCCL3 (a normal rat thyroid cell } \\
\text { line) }\end{array}$ & $\begin{array}{l}\text { Induction of autophagy at the basal } \\
\text { level, but inhibition of RET/PTC- } \\
\text { enhanced autophagy }\end{array}$ & - & [99] \\
\hline & $\begin{array}{l}\text { TPC1 and FTC-236 (PTEN } \text { R }^{\text {R130Ter }} \\
\left.\text { TERT }^{228 C>T} \text {, and p } 53^{R 273 H}\right)\end{array}$ & Inhibition of autophagy & - & \\
\hline
\end{tabular}

TRAIL: tumor necrosis factor-related apoptosis inducing ligand; FAM129A: family with sequence similarity 129 member A 
levels were determined in WB in the BANCR study ${ }^{[58]}$. Tyrosine kinase inhibitors are recently approved as a new thyroid cancer therapeutic regimen, especially RAI-refractory thyroid cancer. In this regard, the relationship between tyrosine kinase inhibitors' anti-cancer effect and autophagy is clinically of interest, but the data on vemurafenib (CQ or 3-MA alone showed no cytotoxic effect but enhanced the vemurafenib's effect $^{[70,76]}$ ) and sorafenib (see the NOTE above ${ }^{[68]}$ ) are not consistent. More complicatedly, there is a report that vemurafenib-induced autophagy is anti-survival in melanoma cells with $\mathrm{BRAF}^{\mathrm{V} 600 \mathrm{E}[84]}$ that is otherwise pro-survival ${ }^{[83]}$ in thyroid cancer cells as mentioned above ${ }^{[70]}$.

(2) Studies reporting anti-survival/proliferative effect of autophagy on thyroid cancer

On the other hand, there are also some articles reporting the anti-survival/proliferative effects of autophagy on thyroid cancers [Table 2], which include autophagy inhibitors of baculoviral IAP repeat containing 7 (BIRC7) ${ }^{[85]}$ and miRNA-221/222 ${ }^{[86]}$, and autophagy inducers such as natural compounds (e.g., sanguinarine ${ }^{[87]}$, aloperine ${ }^{[88]}$, allicin ${ }^{[89]}$, mulberry anthocyanin ${ }^{[90]}$, and apigenin ${ }^{[75]}$ ), long non-coding RNA GAS8 antisense RNA1 (lncRNA GAS8-AS1) ${ }^{[91]}$, doxorubicin ${ }^{[92]}$, radiation ${ }^{[92]}$, RAD001 (everolimus, an mTOR inhibitor) ${ }^{[93]}$, and Sirtuin $6^{[94]}$. NOTE - (1) although Lin et al. ${ }^{[92]}$ used doxorubicin as an autophagy inducer because it increased LC3-II levels (p62 levels were not studied), it is shown in other papers that doxorubicin blocks autophagy at the late stage (therefore increases both LC3-II and p62, like CQ) by impairing lysosomal acidification ${ }^{[95-97]}$; (2) the interpretation of the data on aloperine is difficult - alopeirne increased both LC3-II and p62 levels but further increase in LC3-II could not be seen in combination of aloperine and CQ indicating aloperine-inhibition of autophagy as mentioned earlier, while the red fluorescence in aloperine-treated cells and yellow in aloperine and CQ-treated cells transfected with the mRFP-EGFP-LC3 vector suggest aloperine-induction of autophagy ${ }^{[88]}$; and (3) the effect of anthocyanin on autophagy was only studied by LC3-II levels in WB and formation of autophagosome by electron microscopy and the GFP-LC3 vector but not by p62 levels or formation of autolysosome ${ }^{[90]}$.

Inconsistent data between Tables 1 and 2 include (1) mTOR inhibitors CZ415 and RAD001 show the opposite effects, pro-survival using TPC1 in the former ${ }^{[73]}$ and anti-survival using TPC1 and $8505 \mathrm{C}$ cells in the latter ${ }^{[93]}$; and (2) radiation is also reported to be pro-survival in SW-579 cells ${ }^{[74]}$ and anti-survival in TPC1 and $8505 \mathrm{C}$ cells $^{[92]}$.

(3) Studies reporting context-dependent effect of autophagy on thyroid cancer The third group, context-dependent effect of autophagy on cell survival/proliferation, is also reported [Table 3]. Thus, tumor necrosis factor-related apoptosis inducing ligand (TRAIL) induced autophagy and cell death in TPC 1 cells, and the cell death effect of TRAIL was ameliorated by ATG7 siRNA, indicating anti-survival effect of TRAIL-induced autophagy, while in FRO cells, only cell death, not autophagy, was induced by TRAIL, but, similar to TPC1, TRAIL-induced cell death was impaired by ATG7 siRNA, indicating antisurvival effect of basal level of autophagy (NOTE - only LC3-II levels were determined in TRAIL-treated TPC1 cells. $)^{[98]}$. In another study, family with sequence similarity 129 member A (FAM129A) induced autophagy in parental PCCL3 cells, but inhibited RET/PTC-induced autophagy in RET/PTC-transfected PCCL3 and thyroid cancer cell lines PTC1 and FTC-236 (NOTE - mCherry-eGFP-LC3B produced yellow color in FAM129A-transfected PCCL3 cells, indicating FAM129A-inhibition, not induction, of autophagy. $)^{[99]}$.

\section{(4) Possible reasons for inconsistent data}

Although the reason(s) for these discrepant data are at present unclear, possible explanations are discussed below.

Obviously, autophagy is originally recognized as a pro-survival stress response, so that it is not difficult to acknowledge the pro-survival effect of autophagy on cancer cells. Indeed autophagy in general inhibits apoptosis (and vice versa), albeit with some exceptions ${ }^{[19]}$ (see below), thereby autophagy inhibition 
increases cell death, and cell-survival effects of various autophagy inducers are abolished by autophagy inhibitors as summarized in Table 1. However, there are indeed some exceptions for autophagy-inhibition of apoptosis; for example, autophagy degrades pro-survival factor caveolin-1, activates caspase 8 , and plays a role as scaffolds for apoptosis execution ${ }^{[19]}$. Furthermore, autophagy is reported to be a back-up mechanism for death of cells defective in or resistant to apoptosis during development ${ }^{[100]}$, and in cancer cells ${ }^{[101]}$. Therefore, the consequence of modulation of autophagic activity may be dependent on the sensitivity/resistance of the cancer cells to apoptotic stimuli; apoptosis-resistant cells may be vulnerable to autophagy inducers. Autophagy is also known to modulate other types of cell death ${ }^{[19]}$ which, however, have never been studied in the thyroid cells.

The degree of dependency on or addiction to autophagy in cancer cells may determine response to autophagy modulators ${ }^{[102]}$. Autophagy dependency is reportedly controlled by p53 status, RAS/RAF family status, JAK/STAT/PI3K signaling pathways, and so on. In fact, BRAF ${ }^{\mathrm{V} 600 \mathrm{E}}$ promotes autophagy dependence in multiple tumors ${ }^{[37,102-104]}$, presumably as do RAS and RET/PTC. Thus, thyroid cancers, most of them have mutant RAS/RAF or RET/PTC, likely depend on autophagy for their proliferation/survival.

There are also some lines of evidence supporting anti-survival/proliferative effect of autophagy. The autophagic machinery executes specific forms of cell death, called "autophagic cell death" or "autophagydependent cell death" ${ }^{\text {[19,20,105] }}$. The mechanisms include: (1) over-eating due to excessive-consumption of cellular organelles and cytoplasmic contents; (2) excessive mitophagy leading depletion of mitochondria and consequent energy failure; and (3) autosis by activation of $\mathrm{Na}^{+} / \mathrm{K}^{+}$ATPase pump and changes in membrane osmolarity and ion transporter. In this regard, it may be worth noting here that Li et al. ${ }^{[73]}$ mentioned that "although sustained and profound autophagy activation could promote cell death (autophagic cell death), drug-induced feedback autophagy activation is mostly gentle and has pro-survival ability especially in cancer cells". It is also of interest that rosuvastatin (a statin) induced autophagy at lower concentrations, which shifted to apoptosis with higher concentrations, in BCPAP cells ${ }^{[106]}$. More recently, dendrogenin A (DDA), which is a cholesterol-derived metabolite and a ligand of the liver X receptor and is reported to induce lethal autophagy in other cancer cells ${ }^{[107]}$, was demonstrated to induce cell death/ cell cycle arrest and re-differentiation in thyroid cancer cell lines, B-CPAP and 8505C, although the consequence of autophagy inhibition from DDA is not evaluated ${ }^{[108]}$.

Autophagy also controls thyroid differentiation status. Thus, there is a significant association between LC3 puncta and RAI uptake capacity/solute carrier family 5 member 5 [SLC5A5, or sodium/iodine symporter (NIS)] expression/clinical response to RAI ${ }^{[54]}$. Experimentally, some of autophagy inducers (all are digitalislike compounds) increased RAI uptake in at least one of three PTC or FTC cell lines (BCPAP, TPC1, and FTC133) and in both ATC lines (8505C and Cal-62) (NOTE - all the autophagy inducers examined did not do so in all the cell lines examined, so that this effect may be attributed to their distinct intrinsic nature, not their autophagy-inducing ability, of digitalis-like compounds and/or different cells used, and also whether this effect is abolished by an autophagy inhibitor or not should be addressed. $)^{[109,110]}$.

Keeping all these possibilities in mind (summarized in Figure 3), although currently researchers mainly focus on autophagy inhibitors as a therapeutic modality for thyroid cancer, excess autophagy should also be considered as another choice.

Finally, of interest, intra-nuclear cytoplasmic inclusion, known as one of the diagnostic criteria for PTCs, is recently reported to be formed by nuclear invagination and contain autophagy-related proteins such as LC3, p62, ubiquitin, and cathepsin $\mathrm{B} / \mathrm{D}$, and also $\mathrm{BRAF}^{\mathrm{V} 60 \mathrm{E}[111]}$, although its clinical significance remains to be elucidated. 


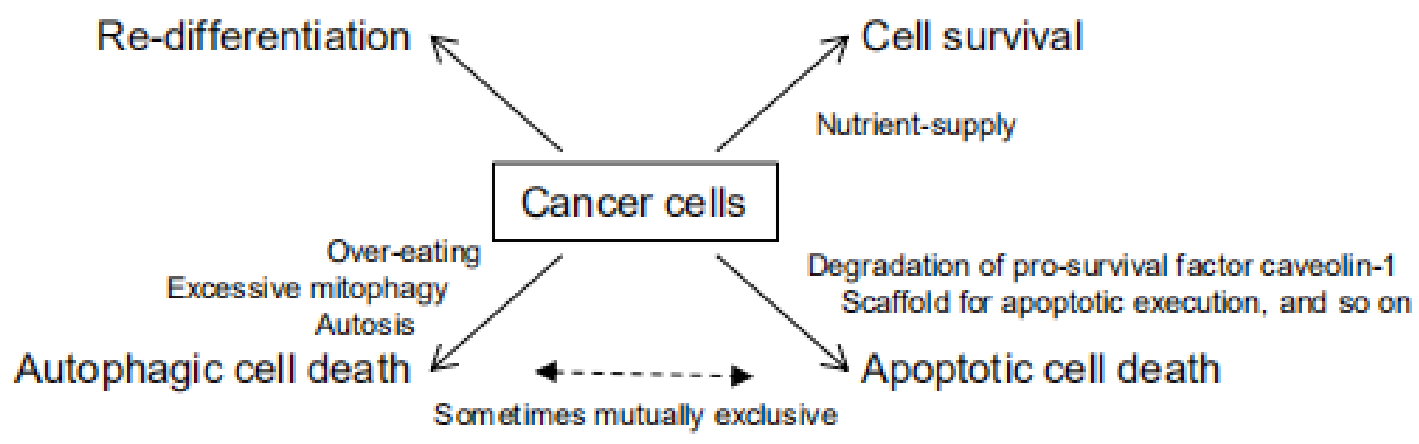

Figure 3. The consequences of autophagy activation in cancer cell phenotype/fate. Autophagy contributes cancer cell survival by providing nutrients, but conversely can induce apoptotic or autophagic cell death. Autophagy also re-differentiates cancer cell

\section{CONCLUSION}

The physiological role for autophagy in the thyroid is relatively clear that studies with genetically engineered mice show that basal level of autophagy is required for maintenance of cell homeostasis and survival, and elevated autophagy, in TSH-stimulated condition, is needed for providing building blocks for sufficient synthesis of proteins including TG. Regarding its pathological role in thyroid cancer initiation, there is some evidence indicating anti-tumorigenic effect of autophagy on cancer initiation in general, but so far nothing in thyroid cancer. Regarding thyroid cancer progression and autophagy-targeted treatment, the data are controversial, some reporting pro-survival/proliferative, but others showing anti-survival/ proliferative and context-dependent effects of autophagy on thyroid cancer. Further studies are needed to elucidate the molecular mechanisms for the complex relationship between autophagy and its effect on thyroid cancer behaviors. Finally, precise monitoring of autophagic flux is highly critical for these studies.

\section{DECLARATIONS}

\section{Authors' contributions}

The author contributed solely to the article.

\section{Availability of data and materials}

Not applicable.

\section{Financial support and sponsorship}

This work was in part supported by the Japan Society for the Promotion of Science (KAKENHI Grant No. 19K09028).

\section{Conflicts of interest}

The author declared that there are no conflicts of interest.

\section{Ethical approval and consent to participate}

Not applicable.

\section{Consent for publication}

Not applicable.

\section{Copyright}

(c) The Author(s) 2021. 


\section{REFERENCES}

1. Vigneri R, Malandrino P, Vigneri P. The changing epidemiology of thyroid cancer: why is incidence increasing? Curr Opin Oncol 2015;27:1-7.

2. The Cancer Genome Atlas Research N. Integrated genomic characterization of papillary thyroid carcinoma. Cell 2014;159:676-90.

3. Ravanan P, Srikumar IF, Talwar P. Autophagy: the spotlight for cellular stress responses. Life Sci 2017;188:53-67.

4. Ravikumar B, Sarkar S, Davies JE, et al. Regulation of mammalian autophagy in physiology and pathophysiology. Physiol Rev 2010;90:1383-435.

5. Klionsky DJ, Abdelmohsen K, Abe A, et al. Guidelines for the use and interpretation of assays for monitoring autophagy (3rd edition). Autophagy 2016;12:1-222.

6. Seglen PO, Gordon PB. 3-Methyladenine: specific inhibitor of autophagic/lysosomal protein degradation in isolated rat hepatocytes. Proc Natl Acad Sci U S A 1982;79:1889-92.

7. Fedorko M. Effect of chloroquine on morphology of cytoplasmic granules in maturing human leukocytes--an ultrastructural study. $J$ Clin Invest 1967;46:1932-42.

8. Fujita K, Maeda D, Xiao Q, Srinivasula SM. Nrf2-mediated induction of p62 controls Toll-like receptor-4-driven aggresome-like induced structure formation and autophagic degradation. Proc Natl Acad Sci U S A 2011;108:1427-32.

9. Nakaso K, Yoshimoto Y, Nakano T, et al. Transcriptional activation of p62/A170/ZIP during the formation of the aggregates: possible mechanisms and the role in Lewy body formation in Parkinson's disease. Brain Res 2004;1012:42-51.

10. Trocoli A, Bensadoun P, Richard E, et al. p62/SQSTM1 upregulation constitutes a survival mechanism that occurs during granulocytic differentiation of acute myeloid leukemia cells. Cell Death Differ 2014;21:1852-61.

11. Kurashige T, Nakajima Y, Shimamura M, Yamada M, Nagayama Y. Hormonal regulation of autophagy in thyroid PCCL3 cells and the thyroids of male mice. J Endocr Soc 2020;4:054.

12. Mizushima N, Yoshimori T. How to interpret LC3 immunoblotting. Autophagy 2007;3:542-5.

13. Komatsu M, Waguri S, Ueno T, et al. Impairment of starvation-induced and constitutive autophagy in Atg7-deficient mice. J Cell Biol 2005; 169:425-34.

14. Kuma A, Hatano M, Matsui M, et al. The role of autophagy during the early neonatal starvation period. Nature 2004;432:1032-6.

15. Komatsu M, Waguri S, Chiba $\mathrm{T}$, et al. Loss of autophagy in the central nervous system causes neurodegeneration in mice. Nature 2006;441:880-4.

16. Hara T, Nakamura K, Matsui M, et al. Suppression of basal autophagy in neural cells causes neurodegenerative disease in mice. Nature 2006;441:885-9.

17. Nakai A, Yamaguchi O, Takeda T, et al. The role of autophagy in cardiomyocytes in the basal state and in response to hemodynamic stress. Nat Med 2007;13:619-24.

18. Ebato C, Uchida T, Arakawa M, et al. Autophagy is important in islet homeostasis and compensatory increase of beta cell mass in response to high-fat diet. Cell Metab 2008;8:325-32.

19. Napoletano F, Baron O, Vandenabeele P, Mollereau B, Fanto M. Intersections between regulated cell death and autophagy. Trends Cell Biol 2019;29:323-38.

20. Bialik S, Dasari SK, Kimchi A. Autophagy-dependent cell death - where, how and why a cell eats itself to death. $J$ Cell Sci 2018;131:jcs215152.

21. Kurashige T, Nakajima Y, Shimamura M, et al. Basal autophagy deficiency causes thyroid follicular epithelial cell death in mice. Endocrinology 2019;160:2085-92.

22. Grieco G, Wang T, Delcorte O, et al. Class III PI3K Vps34 controls thyroid hormone production by regulating thyroglobulin iodination, lysosomal proteolysis, and tissue homeostasis. Thyroid 2020;30:133-46.

23. Galluzzi L, Green DR. Autophagy-independent functions of the autophagy machinery. Cell 2019;177:1682-99.

24. Levy JMM, Towers CG, Thorburn A. Targeting autophagy in cancer. Nat Rev Cancer 2017;17:528-42.

25. Wei WJ, Hardin H, Luo QY. Targeting autophagy in thyroid cancers. Endocr Relat Cancer 2019;26:R181-94.

26. Singh SS, Vats S, Chia AY, Tan TZ, Deng S, et al. Dual role of autophagy in hallmarks of cancer. Oncogene 2018;37:1142-58.

27. Qu XP, Yu J, Bhagat G, et al. Promotion of tumorigenesis by heterozygous disruption of the beclin 1 autophagy gene. J Clin Invest 2003;112:1809-20.

28. Yue ZY, Jin SK, Yang CW, Levine AJ, Heintz N. Beclin 1, an autophagy gene essential for early embryonic development, is a haploinsufficient tumor suppressor. Proc Natl Acad Sci U S A 2003;100:15077-82.

29. Takamura A, Komatsu M, Hara T, et al. Autophagy-deficient mice develop multiple liver tumors. Genes Dev 2011;25:795-800.

30. Inami Y, Waguri S, Sakamoto A, Kouno T, Nakada K, et al. Persistent activation of Nrf2 through p62 in hepatocellular carcinoma cells. $J$ Cell Biol 2011;193:275-84.

31. Mathew R, Karp CM, Beaudoin B, et al. Autophagy suppresses tumorigenesis through elimination of p62. Cell 2009;137:1062-75.

32. Liang XH, Kleeman LK, Jiang HH, et al. Protection against fatal Sindbis virus encephalitis by beclin, a novel Bcl-2-interacting protein. $J$ Virol 1998;72:8586-96.

33. Liu JL, Xia HG, Kim MS, et al. Beclin1 controls the levels of p53 by regulating the deubiquitination activity of USP10 and USP13. Cell 2011;147:223-34

34. Kimmelman AC. The dynamic nature of autophagy in cancer. Genes Dev 2011;25:1999-2010.

35. Rebecca VW, Amaravadi RK. Emerging strategies to effectively target autophagy in cancer. Oncogene 2016;35:1-11.

36. Rao S, Tortola L, Perlot T, et al. A dual role for autophagy in a murine model of lung cancer. Nat Commun 2014;5:3056. 
37. Strohecker AM, Guo JY, Karsli-Uzunbas G, et al. Autophagy sustains mitochondrial glutamine metabolism and growth of BrafV600Edriven lung tumors. Cancer Discov 2013;3:1272-85.

38. Karsli-Uzunbas G, Guo JY, Price S, et al. Autophagy is required for glucose homeostasis and lung tumor maintenance. Cancer Discov 2014;4:914-27.

39. Rosenfeldt MT, O'Prey J, Morton JP, et al. p53 status determines the role of autophagy in pancreatic tumour development. Nature 2013;504:296-300.

40. Iacobuzio-Donahue CA, Herman JM. Autophagy, p53, and pancreatic cancer. N Engl J Med 2014;370:1352-3.

41. Lock R, Roy S, Kenific CM, et al. Autophagy facilitates glycolysis during Ras-mediated oncogenic transformation. Mol Biol Cell 2011;22:165-78

42. Bae H, Guan JL. Suppression of autophagy by FIP200 deletion impairs DNA damage repair and increases cell death upon treatments with anticancer agents. Mol Cancer Res 2011;9:1232-41.

43. Gillespie DA, Ryan KM. Autophagy is critically required for DNA repair by homologous recombination. Mol Cell Oncol 2016;3:e1030538.

44. Yu WF, Ni Y, Saji M, Ringel MD, Jaini R, Eng C. Cowden syndrome-associated germline succinate dehydrogenase complex subunit D (SDHD) variants cause PTEN-mediated down-regulation of autophagy in thyroid cancer cells. Hum Mol Genet 2017;26:1365-75.

45. Plantinga TS, van de Vosse E, Huijbers A, et al. Role of genetic variants of autophagy genes in susceptibility for non-medullary thyroid cancer and patients outcome. PLoS One 2014;9:e94086.

46. Huijbers A, Plantinga TS, Joosten LA, et al. The effect of the ATG16L1 Thr300Ala polymorphism on susceptibility and outcome of patients with epithelial cell-derived thyroid carcinoma. Endocr Relat Cancer 2012;19:L15-8.

47. Mussazhanova Z, Shimamura M, Kurashige T, Ito M, Nakashima M, Nagayama Y. Causative role for defective expression of mitochondria-eating protein in accumulation of mitochondria in thyroid oncocytic cell tumors. Cancer Sci 2020;111:2814-23.

48. Miyamoto Y, Kitamura N, Nakamura Y, Futamura M, Miyamoto T, et al. Possible existence of lysosome-like organella within mitochondria and its role in mitochondrial quality control. PLoS One 2011;6:e16054.

49. Bonora E, Evangelisti C, Bonichon F, Tallini G, Romeo G. Novel germline variants identified in the inner mitochondrial membrane transporter TIMM44 and their role in predisposition to oncocytic thyroid carcinomas. Br J Cancer 2006;95:1529-36.

50. Lee J, Ham S, Lee MH, Kim SJ, Park JH, et al. Dysregulation of Parkin-mediated mitophagy in thyroid Hurthle cell tumors. Carcinogenesis 2015;36:1407-18

51. Ganly I, Makarov V, Deraje S, Dong Y, Reznik E, et al. Integrated genomic analysis of Hurthle cell cancer reveals oncogenic drivers, recurrent mitochondrial mutations, and unique chromosomal landscapes. Cancer Cell 2018;34:256-70.e5.

52. Zhang N, Li LC, Wang J, et al. Study of autophagy-related protein light chain 3 (LC3)-II expression levels in thyroid diseases. Biomed Pharmacother 2015;69:306-10.

53. Jiang NN, Yang Y, Zhao GN, et al. Knockout of ASAP1 induces autophagy in papillary thyroid carcinoma by inhibiting the mTOR signaling pathway. Pathol Res Pract 2020;216:152950.

54. Plantinga TS, Tesselaar MH, Morreau H, et al. Autophagy activity is associated with membranous sodium iodide symporter expression and clinical response to radioiodine therapy in non-medullary thyroid cancer. Autophagy 2016;12:1195-205.

55. Kinsey CG, Camolotto SA, Boespflug AM, et al. Protective autophagy elicited by RAF-->MEK-->ERK inhibition suggests a treatment strategy for RAS-driven cancers. Nat Med 2019;25:620-7.

56. Faustino A, Couto JP, Pópulo H, et al. mTOR pathway overactivation in BRAF mutated papillary thyroid carcinoma. J Clin Endocrinol Metab 2012;97:E1139-49.

57. Morani F, Titone R, Pagano L, et al. Autophagy and thyroid carcinogenesis: genetic and epigenetic links. Endocr Relat Cancer 2014;21:R13-29.

58. Wang Y, Guo QH, Zhao Y, et al. BRAF-activated long non-coding RNA contributes to cell proliferation and activates autophagy in papillary thyroid carcinoma. Oncol Lett 2014;8:1947-52.

59. Corazzari M, Rapino F, Ciccosanti F, et al. Oncogenic BRAF induces chronic ER stress condition resulting in increased basal autophagy and apoptotic resistance of cutaneous melanoma. Cell Death Differ 2015;22:946-58.

60. Liu YL, Lai F, Wilmott JS, et al. Noxa upregulation by oncogenic activation of MEK/ERK through CREB promotes autophagy in human melanoma cells. Oncotarget 2014;5:11237-51.

61. Kim HM, Kim ES, Koo JS. Expression of autophagy-related proteins in different types of thyroid cancer. Int J Mol Sci 2017;18.

62. Li X, Xu H, Ma H. Beclin 1 is highly expressed in papillary thyroid carcinoma and correlates with lymph node metastasis. Acta Chir Belg 2013;113:175-81.

63. Song HJ, Chen XY, Jiao Q, et al. HIF-1 $\alpha$-mediated TERT activation inducing autophagy through mTOR promotes papillary thyroid carcinoma progression during hypoxia stress. Thyroid 2020.

64. Hu G, Feng HF, Zhan H. Identification of an autophagy-related signature predicting overall survival for papillary thyroid carcinoma. Dose Response 2020;18:1559325819899265.

65. Zhu HW, Qu YQ. Expression levels of ARHI and Beclin1 in thyroid cancer and their relationship with clinical pathology and prognosis. Oncol Lett 2020;19:1241-6.

66. Zhang DX, Xu XN, Li JJ, et al. High iodine effects on the proliferation, apoptosis, and migration of papillary thyroid carcinoma cells as a result of autophagy induced by BRAF kinase. Biomed Pharmacother 2019;120:109476.

67. Hong Z, Xin X, Ying C, et al. Chaperone-mediated autophagy governs progression of papillary thyroid carcinoma via PPAR $\gamma$-SDF1/ CXCR4 signaling. J Clin Endocrinol Metab 2020;105:dgaa366. 
68. Yi HQ, Ye T, Ge MH, et al. Inhibition of autophagy enhances the targeted therapeutic effect of sorafenib in thyroid cancer. Oncol Rep 2018;39:711-20.

69. Fan D, Liu SY, van Hasselt CA, et al. Estrogen receptor alpha induces prosurvival autophagy in papillary thyroid cancer via stimulating reactive oxygen species and extracellular signal regulated kinases. J Clin Endocrinol Metab 2015;100:E561-71.

70. Wang WB, Kang H, Zhao YN, et al. Targeting autophagy sensitizes BRAF-mutant thyroid cancer to vemurafenib. J Clin Endocrinol Metab 2017;102:634-43.

71. Feng HR, Cheng X, Kuang J, et al. Apatinib-induced protective autophagy and apoptosis through the AKT-mTOR pathway in anaplastic thyroid cancer. Cell Death Dis 2018;9:1030.

72. Meng XR, Wang HJ, Zhao JZ, et al. Apatinib inhibits cell proliferation and induces autophagy in human papillary thyroid carcinoma via the PI3K/Akt/mTOR signaling pathway. Front Oncol 2020;10:217.

73. Li XB, Li ZZ, Song YM, Liu WG, Liu ZW. The mTOR kinase inhibitor CZ415 inhibits human papillary thyroid carcinoma cell growth. Cell Physiol Biochem 2018;46:579-90.

74. Gao P, Hao FJ, Dong X, Qiu Y. The role of autophagy and Beclin-1 in radiotherapy-induced apoptosis in thyroid carcinoma cells. Int $J$ Clin Exp Pathol 2019;12:885-92.

75. Zhang L, Cheng X, Gao YY, et al. Apigenin induces autophagic cell death in human papillary thyroid carcinoma BCPAP cells. Food Funct 2015;6:3464-72.

76. Run L, Wang LP, Nong XT, Li N, Huang X, Xiao Y. Involvement of HMGB1 in vemurafenib resistance in thyroid cancer cells harboring BRAF (V600E) mutation by regulating excessive autophagy. Endocrine 2020.

77. Morgan MJ, Fitzwalter BE, Owens CR, et al. Metastatic cells are preferentially vulnerable to lysosomal inhibition. Proc Natl Acad Sci U S A 2018;115:E8479-e88.

78. Maycotte P, Aryal S, Cummings CT, et al. Chloroquine sensitizes breast cancer cells to chemotherapy independent of autophagy. Autophagy 2012;8:200-12.

79. Lee HO, Mustafa A, Hudes GR, Kruger WD. Hydroxychloroquine destabilizes phospho-S6 in human renal carcinoma cells. PLoS One 2015;10:e0131464.

80. Liu J, Feng LG, Zhang HT, et al. Effects of miR-144 on the sensitivity of human anaplastic thyroid carcinoma cells to cisplatin by autophagy regulation. Cancer Biol Ther 2018;19:484-96.

81. Zhang Y, Yang WQ, Zhu H, et al. Regulation of autophagy by miR-30d impacts sensitivity of anaplastic thyroid carcinoma to cisplatin. Biochem Pharmacol 2014;87:562-70.

82. He Q, Liu WP, Sha S, et al. Adenosine 5'-monophosphate-activated protein kinase-dependent mTOR pathway is involved in flavokawain B-induced autophagy in thyroid cancer cells. Cancer Sci 2018;109:2576-89.

83. Li S, Zhang HY, Wang T, et al. BAG3 promoted starvation-induced apoptosis of thyroid cancer cells via attenuation of autophagy. $J$ Clin Endocrinol Metab 2014;99:E2298-307.

84. Zhao YN, Wang WB, Min I, et al. BRAF V600E-dependent role of autophagy in uveal melanoma. J Cancer Res Clin Oncol 2017;143:447-55.

85. Liu KP, Yu QG, Li H, et al. BIRC7 promotes epithelial-mesenchymal transition and metastasis in papillary thyroid carcinoma through restraining autophagy. Am J Cancer Res 2020;10:78-94.

86. Shen H, Lin ZK, Shi HY, et al. MiR-221/222 promote migration and invasion, and inhibit autophagy and apoptosis by modulating ATG10 in aggressive papillary thyroid carcinoma. 3 Biotech 2020;10:339.

87. Khan AQ, Mohamed EAN, Hakeem I, et al. Sanguinarine induces apoptosis in papillary thyroid cancer cells via generation of reactive oxygen species. Molecules 2020;25:1229.

88. Yu HI, Shen HC, Chen SH, et al. Autophagy modulation in human thyroid cancer cells following aloperine treatment. Int J Mol Sci 2019;20.

89. Xiang YF, Zhao JQ, Zhao M, Wang KJ. Allicin activates autophagic cell death to alleviate the malignant development of thyroid cancer. Exp Ther Med 2018;15:3537-43.

90. Long HL, Zhang FF, Wang HL, et al. Mulberry anthocyanins improves thyroid cancer progression mainly by inducing apoptosis and autophagy cell death. Kaohsiung J Med Sci 2018;34:255-62.

91. Qin Y, Sun W, Zhang H, et al. LncRNA GAS8-AS1 inhibits cell proliferation through ATG5-mediated autophagy in papillary thyroid cancer. Endocrine 2018;59:555-64.

92. Lin CI, Whang EE, Abramson MA, et al. Autophagy: a new target for advanced papillary thyroid cancer therapy. Surgery 2009;146:1208-14.

93. Lin CI, Whang EE, Donner DB, et al. Autophagy induction with RAD001 enhances chemosensitivity and radiosensitivity through Met inhibition in papillary thyroid cancer. Mol Cancer Res 2010;8:1217-26.

94. Yang Z, Huang RH, Wei XY, Yu WP, Min ZJ, Ye M. The SIRT6-Autophagy-Warburg effect axis in papillary thyroid cancer. Front Oncol 2020;10:1265.

95. Xu XH, Bucala R, Ren J. Macrophage migration inhibitory factor deficiency augments doxorubicin-induced cardiomyopathy. J Am Heart Assoc 2013;2:e000439-e.

96. Kawaguchi T, Takemura G, Kanamori H, et al. Prior starvation mitigates acute doxorubicin cardiotoxicity through restoration of autophagy in affected cardiomyocytes. Cardiovasc Res 2012;96:456-65.

97. Li DL, Wang ZV, Ding G, et al. Doxorubicin blocks cardiomyocyte autophagic flux by inhibiting Lysosome acidification. Circulation 2016;133:1668-87. 
98. Jin SM, Jang HW, Sohn SY, et al. Role of autophagy in the resistance to tumour necrosis factor-related apoptosis-inducing ligand-induced apoptosis in papillary and anaplastic thyroid cancer cells. Endocrine 2014;45:256-62.

99. Nozima BH, Mendes TB, Pereira G, et al. FAM129A regulates autophagy in thyroid carcinomas in an oncogene-dependent manner. Endocr Relat Cancer 2019;26:227-38.

100. Arakawa S, Tsujioka M, Yoshida T, et al. Role of Atg5-dependent cell death in the embryonic development of Bax/Bak double-knockout mice. Cell Death Differ 2017;24:1598-608.

101. Fulda S, Kögel D. Cell death by autophagy: emerging molecular mechanisms and implications for cancer therapy. Oncogene 2015;34:5105-13.

102. Maycotte P, Gearheart CM, Barnard R, et al. STAT3-mediated autophagy dependence identifies subtypes of breast cancer where autophagy inhibition can be efficacious. Cancer Res 2014;74:2579-90.

103. Levy JM, Thompson JC, Griesinger AM, et al. Autophagy inhibition improves chemosensitivity in BRAF(V600E) brain tumors. Cancer Discov 2014;4:773-80.

104. Xie X, Koh JY, Price S, White E, Mehnert JM. Atg7 overcomes senescence and promotes growth of BrafV600E-driven melanoma. Cancer Discov 2015;5:410-23.

105. Galluzzi L, Vitale I, Aaronson SA, et al. Molecular mechanisms of cell death: recommendations of the Nomenclature Committee on Cell Death 2018. Cell Death Differ 2018;25:486-541.

106. Zeybek ND, Gulcelik NE, Kaymaz FF, et al. Rosuvastatin induces apoptosis in cultured human papillary thyroid cancer cells. $J$ Endocrinol 2011;210:105-15.

107. Pontini L, Marinozzi M. Shedding light on the roles of liver X receptors in cancer by using chemical probes. Br J Pharmacol 2020.

108. Bauriaud-Mallet M, Vija-Racaru L, Brillouet S, et al. The cholesterol-derived metabolite dendrogenin A functionally reprograms breast adenocarcinoma and undifferentiated thyroid cancer cells. J Steroid Biochem Mol Biol 2019;192:105390.

109. Tesselaar MH, Crezee T, Swarts HG, Gerrits D, Boerman OC, et al. Digitalis-like compounds facilitate non-medullary thyroid cancer redifferentiation through intracellular Ca2+, FOS, and autophagy-dependent pathways. Mol Cancer Ther 2017;16:169-81.

110. Tesselaar MH, Crezee T, Schuurmans I, et al. Digitalislike compounds restore hNIS expression and iodide uptake capacity in anaplastic thyroid cancer. $J$ Nucl Med 2018;59:780-6.

111. Schwertheim S, Theurer S, Jastrow H, et al. New insights into intranuclear inclusions in thyroid carcinoma: association with autophagy and with BRAFV600E mutation. PLoS One 2019;14:e0226199.

112. Landa I, Pozdeyev N, Korch C, Marlow LA, Smallridge RC, et al. Comprehensive genetic characterization of human thyroid cancer cell lines: a validated panel for preclinical studies. Clin Cancer Res 2019;25:3141-51. 